\title{
Diferentes tratamientos de superficies de zirconia y su relación con la unión de los cementos de resina
}

\author{
González-Serna Arturo*, Martín del Campo-Téllez Bryan Iván**, Esparza-Villalpando Vicente*, \\ Flores-Maldonado Adrín Noé***, Yusa Koichiro ${ }^{* * *}$, Masuoka David ${ }^{* * *}$
}

\begin{tabular}{|c|c|}
\hline 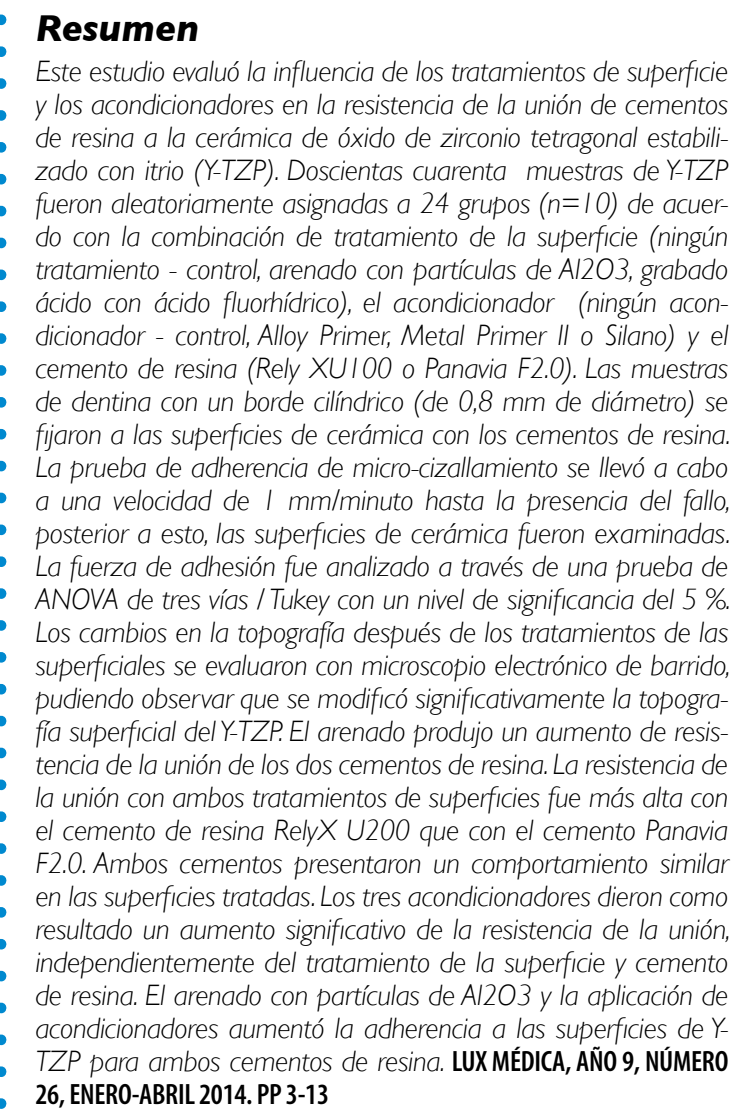 & 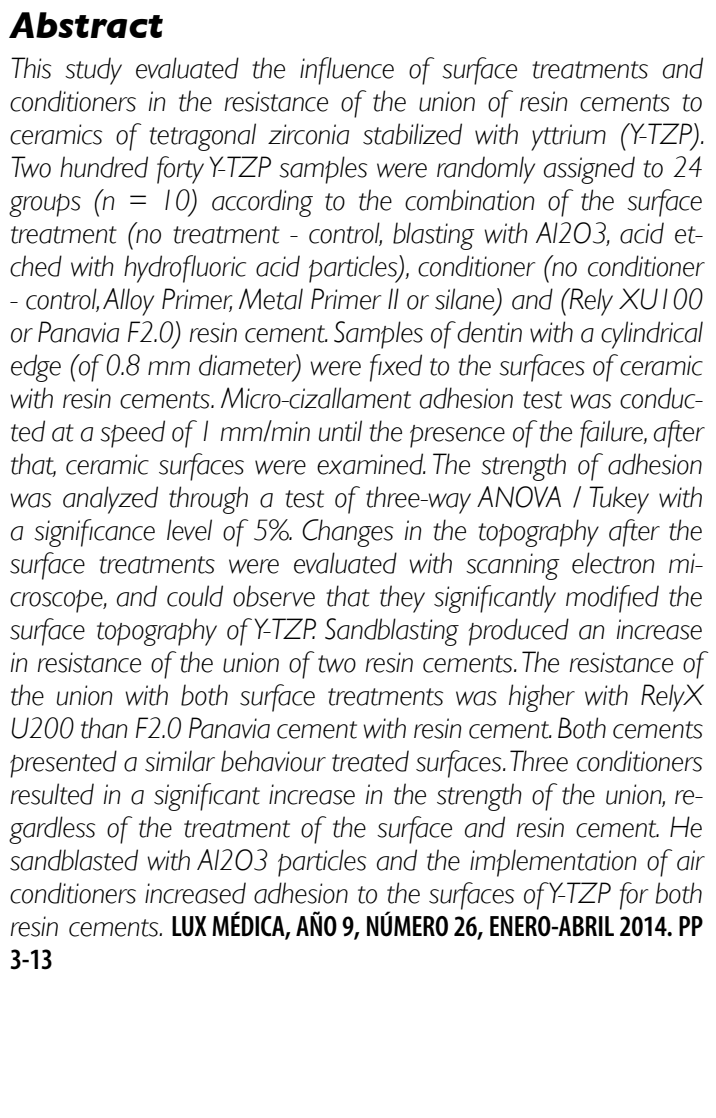 \\
\hline $\begin{array}{r}\text { Palabras Clave: } \\
\qquad a c\end{array}$ & treatment \\
\hline
\end{tabular}

* Docente académico del Departamento de Estomatología del Centro de Ciencias de la Salud de la Universidad Autónoma de Aguascalientes. ** Estudiantes de pregrado de la licenciatura de Estomatología de la Universidad Autónoma de Aguascalientes

*** Profesor investigador del Departamento de Estomatología del Centro de Ciencias de la Salud de la Universidad Autónoma de Aguascalientes.

**** Profesor investigador del Departamento de Prótesis Dental de la Escuela de Posgrado de la Universidad Médico Dental de Tokio

Fecha de recibido: 25 de noviembre 2013

Fecha de aceptación: 25 de enero 2014

Correspondencia: David Masuoka Ito DDS, MMM, PhD. Departamento de Estomatología Centro de Ciencias de la Salud, Universidad Autónoma de Aguascalientes. Av. Aguascalientes No.904, Unidad Médico Didáctica, Edif.101, Ciudad Universitaria, Aguascalientes, Ags. México, CP 20131. Tel: +52 (449) 910 8438. Correo electrónico david.masuoka@gmail.com 


\section{Introducción}

La evolución de los materiales de óxido de zirconio tetragonal estabilizado con itrio ( $Y$-TZP) ha introducido una nueva clase de cerámica dental. ${ }^{1}$ Aunque la zirconia (Y-TZP) se ha utilizado como un biomaterial cerámico en aplicaciones médicas desde finales de la década de 1960, su uso en la odontología es relativamente reciente, produciéndose grandes avances con el uso de la tecnología CAD-CAM (diseño asistido por ordenador / fabricación). ${ }^{1-4}$ Estos materiales de alta resistencia ofrecen una amplia variedad de aplicaciones clínicas, como brackets de ortodoncia, postes, pilares de implantes y cofias para coronas y puentes. ${ }^{5-6}$

Los materiales de Y-TZP difieren de otras cerámicas dentales de alta resistencia debido a su distinto mecanismo de endurecimiento por transformación inducida por el estrés, lo que significa que el material se somete a cambios microestructurales cuando es sometido a estrés. ${ }^{2,4}$ Las cerámicas de Y-TZP pueden resistir activamente la propagación de grietas a través de la transformación de una tetragonal a una fase monolítica en la punta de una grieta, la cual se acompaña de un incremento de volumen. ${ }^{2}$ Las propiedades mecánicas de los materiales de Y-TZP, tales como la flexión y resistencia a la fractura, son considerablemente más altos que los de otros materiales dentales cerámicos. ${ }^{4}$ La resistencia a la flexión de Y-TZP puede alcanzar valores de 700 a $1200 \mathrm{MPa}^{7-8}$ estos valores exceden las cargas oclusales máximas durante la masticación. ${ }^{8}$ Por otra parte, estos materiales también puede exhibir resistencia a la fractura mayor que $2,000 \mathrm{~N}$, que es casi dos veces el valor obtenido para los materiales basados en alúmina, y al menos tres veces el valor demostrado por el disilicato de litio. ${ }^{9}$

A pesar de que la mejora de las propiedades mecánicas es importante para el rendimiento a largo plazo de un material cerámico, el éxito clínico de una prótesis fija libre de metal estará relacionado dependiendo del procedimiento de cementación. Existe una idea de que los métodos convencionales de cementación adhesiva, que incluyen grabado ácido previo de la superficie de cerámica con ácido fluorhídrico y silanización, no son eficientes para las cerámicas de Y-TZP debido a su falta de la fase de sílice y vidrio, 1,3,10 a pesar de que algunos fabricantes de Y-TZP sugieren el uso de abrasión por aire o recubrimiento triboquímico antes de la cementación adhesiva, el efecto de los tratamientos de superficie sobre las propiedades mecánicas de los materiales de Y-TZP es muy controvertido, y ambos resultados positivos y negativos han sido estudiados y descritos en la literatura, ${ }^{11-12}$ por lo tanto, el tratamiento de la superficie más adecuada para la cerámica Y-TZP aún tiene que ser estudiada con una mayor profundidad. Algunos estudios han sugerido el uso de un grabado ácido (ácido fluorhídrico 10\%) para mejorar la resistencia de la unión de los materiales adhesivos resinosos utilizados para restauraciones indirectas y cerámicas basados en óxidos de litio. ${ }^{13-14}$ 
Existe evidencia de que puede lograrse una unión mejorada a la cerámica de Y-TZP utilizando materiales con una afinidad química para óxidos metálicos. ${ }^{1,5,10,15-16}$ Los monómeros de éster fosfato, tales como el MDP (10-methacryloyloxyidecyl- dihyidrogenphosphate), reaccionan con el dióxido de zirconio, promoviendo una unión resistente al agua de la superficie densa de cerámica sinterizada de zirconio..$^{10}$ Los monómeros de éster fosfato pueden estar presentes tanto en los cementos de resina, como en los sistemas adhesivos. En la actualidad se han desarrollado acondicionadores, los metal primers (monómeros adhesivos especiales para mejorar la unión con las aleaciones metálicas), y sus efectos sobre la unión adhesiva a la cerámica de Y-TZP aún no han sido estudiados y evaluados a fondo. Estos metal primers contienen MDP y otros monómeros, incluyendo VBATDT (6-[4-vinilbencil-n- propil]amino-1,3,5triazina-2,4-ditiona), MEPS (metacrilato de tiofosfórico) y MTU-6 (6-methacryloyloxyhexyl-2-tiouracilo-5-carboxilato de metilo). ${ }^{17-18}$ Sin embargo, el efecto del grabado ácido y la interacción con los metal primer para los procedimientos de cementación adhesiva no han sido estudiados a profundidad.

El aumento en el uso clínico odontológico de la zirconia hace necesario el estudiar más sobre la cementación adhesiva de este tipo de restauraciones, para poder establecer las técnicas de cementación más adecuadas y fiables. ${ }^{19}$ Existe la posibilidad de mejorar la adhesión a las cerámicas de Y-TZP por medio de técnicas modernas para tratamientos de superficie y su relación con metal primers los cuales necesitan ser probados. Por lo tanto, el presente estudio evaluó el efecto de diferentes acondicionadores y los métodos de tratamiento de superficies sobre la resistencia de la unión de dos cementos de resina a una superficie de cerámica de Y-TZP y dentina.

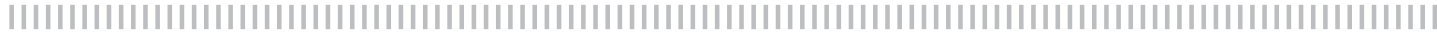

\section{Material y métodos}

Cuarenta terceros molares humanos recientemente extraídos, sin signos de caries se utilizaron para obtener las muestras de dentina. Después de la extracción, los dientes fueron almacenados en solución de timol al 0,1\% por menos de seis meses. Se obtuvieron discos de dentina de 3,5 mm de espesor mediante la eliminación de la parte de la raíz y el esmalte oclusal de cada diente. Los discos de dentina se pulieron con lijas de agua para eliminar los restos de esmalte sobre la superficie de la dentina y para estandarizar la capa de barro dentinario. Los discos se cortaron en la " $\mathrm{x}$ " $y$ el eje " $y$ ", que se tradujo en seis barras de $2 \times 2 \times 3,5 \mathrm{~mm}$ de dimensión. Las barras se colocaron en un instrumento conformador por medio de fresas de diamante finas (515.5 F, Two Sripper, Pennsylvania, EE.UU.) con una pieza de mano de alta velocidad con constante enfriamiento por medio de agua. Después de recortar, los fragmentos cilíndricos tenían una longitud de $1,3 \mathrm{~mm}$ de alto y $0,8 \mathrm{~mm}$ de diámetro. Se obtuvieron doscientos cuarenta especímenes de dentina y se almacenaron en agua destilada a $37^{\circ} \mathrm{C}$. 
Se fabricaron doscientas cuarenta placas de Y-TZP (itrio parcialmente estabilizado con estructura policristalina tetragonal) de cerámica ICE (Zirkonzahn, Gais, Italia) con dimensiones de $5 \times 3 \times 0,75 \mathrm{~mm}$. Estas placas de Y-TZP y las muestras de dentina recortadas fueron distribuidas aleatoriamente en 24 grupos $(n=10)$ de acuerdo con la combinación de tratamiento de superficie, primer y cemento de resina.

Tres grupos con 80 placas de Y-TZP fueron sometidos a uno de los siguientes tratamientos de superficie: ninguno (control), arenado (abrasión con aire) o grabado ácido (ácido fluorhídrico). En los grupos de arenado y grabado ácido, el área de la superficie a tratar $(1,76 \mathrm{~mm} 2)$ fue delimitada con cinta adhesiva. Los tratamientos superficiales se realizaron de la siguiente manera:

- Control: Las muestras sólo se limpiaron con ultrasonido con isopropanol al $96 \%$ durante tres minutos.

- Arenado: Se realizó con partículas de óxido de aluminio de 53 micras Aquacut (Medivance Instruments Ltd., Londres, Reino Unido) a una presión de 2,5 bar durante 15 segundos, a una distancia de $10 \mathrm{~mm}$ perpendicular a la superficie. A continuación, la cinta adhesiva se retiró y las placas se limpiaron ultrasónicamente con isopropanol al $96 \%$ durante tres minutos.

- Grabado ácido: Las superficies fueron grabadas con ácido fluorhídrico al 9.5\% (Porcelain Etch, Ultradent, Utah, EE.UU.) durante 120 segundos. Se procedió a lavar el ácido con agua corriente durante 30 segundos. Después del lavado, la cinta adhesiva se retiró y las superficies se limpiaron ultrasónicamente con isopropanol al $96 \%$ durante tres minutos.
Las 80 placas de cerámica de cada grupo se dividieron en cuatro subgrupos $(n=20)$ : sin acondicionador (control), Alloy Primer (VBATDT/MDP, Kuraray Medical Inc., Okayama, Japón), Metal Primer II (MEPS, GC Corporation, Tokio, Japón) o SILANO (X-R-Si(OR)3n, Angelus, Parana, Brasil). La colocación de los agentes acondicionadores se aplicó en una capa delgada y se dejó reposar durante 60 segundos. Tras el respectivo tratamiento de la superficie y aplicación de los agentes, las 20 placas se dividieron en dos grupos $(n=10)$ de acuerdo con el cemento de resina utilizado: cemento de resina Panavia F2.0 (Kuraray Medical Inc., Tokio, Japón) y cemento de resina RelyX U200 (3M ESPE, Minnesota, EE.UU.). Los especímenes de dentina se cementaron sobre las placas de Y-TZP con las siguientes recomendaciones:

- Panavia F2.0: Se mezclaron cantidades iguales de soluciones de sistemas adhesivos A \& B (ED Primer II) y se aplicaron al cilindro de la dentina. Después de 30 segundos, la capa de adhesivo se secó suavemente con aire. Se mezclaron cantidades iguales de pasta $A \& B$ del cemento de resina durante 20 segundos. Esta mezcla se aplicó a la superficie de la dentina y se colocó la placa de cerámica. El exceso de cemento se eliminó con un explorador dental. Los márgenes se foto-curaron durante 20 segundos, y se bloqueó el oxígeno por medio de gel (Oxyguard II), el cual se aplicó durante tres minutos, luego se lavó con agua y aire a presión.

- RelyX U200: Se mezclaron cantidades iguales de las pastas hasta lograr una mezcla homogénea. Esta mezcla se aplicó a la superficie de la dentina y se colocó la placa de cerámica. Se dejó un minuto para que iniciara el proceso de polimerización. En este momento se retiró el exceso de cemento con un 
explorador dental mientras aún estaba semiduro. Finalmente los márgenes se foto curaron durante 20 segundos.

Una sola capa de mezcla de adhesivo/ activador se aplicó a la superficie de la cerámica y se secó al aire durante cinco segundos. Cantidades iguales de la base y el catalizador del cemento de resina (viscosidad regular) se mezclaron durante 20 segundos. Una capa delgada uniforme de cemento se aplicó sobre la superficie del cilindro de dentina, uniendo ambas superficies, la de cerámica con las de dentina. El excedente de cemento fue retirado de las áreas marginales utilizando el explorador dental. Todas las áreas marginales fueron fotocuradas durante 20 segundos de cada dirección, para un total de 80 segundos de exposición a la luz.

Durante los procedimientos de restauración, la salida de luz de la lámpara de polimerización (Quick Lamp, Zirkonzahn, Gais, Italia) se midió con un radiómetro (Demetron, Kerr Co., California, EE.UU.) y fue mayor que $660 \mathrm{~mW} / \mathrm{cm} 2$. Las muestras se almacenaron en agua destilada a $37{ }^{\circ} \mathrm{C}$ durante 24 horas. Posteriormente, los excedentes de cementos de resina y de adhesivo se eliminaron usando cuchillas de afeitar bajo un microscopio óptico $45 \mathrm{x}$ (SDZ-PL, Kyowa Optical Co, Tokio, Japón).

Cada placa de cerámica con su cilindro de la dentina se fijó a un dispositivo de adaptado a una máquina de prueba de carga en miniatura (SMAC LAL95, SMAC Europa, Sussek, Reino Unido), con pegamento de cianoacrilato (SuperGlue, Loctite, Henkel Loctite, Hertfordshire, Reino Unido). Un alambre delgado $(0,2 \mathrm{~mm}$ de espesor) fue enrollado alrededor de la extremidad del cilindro de dentina y la fuerza de corte se aplicó a una velocidad de avance de $1 \mathrm{~mm} /$ minuto hasta que se presentó el desprendimiento. Los valores $\mathrm{KgF}$ se convirtieron en $\mathrm{MPa}$. Después de la pérdida de la adherencia, las superficies frac- turadas se evaluaron con un microscopio óptico (100x de aumento) para clasificar los modos de fallo en una de las siguientes categorías:

- (A) Falla adhesiva en la interfaz entre la cerámica y el agente de cementación de resina, o entre el agente de cementación de resina y la interfaz de la dentina.

- (C) Falla de cohesión dentro de la cerámica, dentro del agente de cementación de resina, o únicamente dentro de la dentina.

- (M) Falla adhesiva y cohesiva en el mismo sitio o una falla mixta.

Los datos de resistencia de unión se analizaron estadísticamente mediante tres vías ANOVA: con los principales factores de cemento de resina, tratamiento de superficies y colocación de un metal primer. Todas las posibles interacciones se incluyeron en el modelo, y se realizaron múltiples comparaciones por pares por medio de la prueba de Tukey. El análisis estadístico se realizó en SAS 9.1 (SAS Institute, Carolina del Norte, EE.UU.) con un nivel de significación del $5 \%$.

Seis placas adicionales de Y-TZP se examinaron usando microscopía electrónica de barrido (MEB), para evaluar los cambios en la topografía de cerámica después de los tratamientos de superficie. Las placas de cerámica $(n=2$ para cada grupo de tratamiento de la superficie) fueron tratados y limpiados como se ha descrito anteriormente. Posteriormente se colocaron en un talón metálico, manteniendo la superficie tratada cara arriba, las cuales fueron recubiertas con oro por pulverización catódica (E5100, Polaron Equipment Ltd, Hertfordshire, Reino Unido) y se realizaron las observaciones en el microscopio electrónico de barrido (JSM-5900LV, JEOL, Tokio, Japón). 


\section{Resultados}

La tabla 1 muestra los resultados de la resistencia de unión. Se detectó una interacción estadísticamente significativa entre los cementos de resina y los tratamientos de superficie $(p=0,004)$. Por lo tanto, la asociación entre estos dos factores principales fue similar en los cuatro niveles de los factores relacionados con los acondicionado- res, como el metal primer y el silano. Una diferencia significativa se observó también en el factor del agente acondicionador $(p<0,01)$, detectando que las tres soluciones utilizadas como recubrimiento aumentaron la resistencia de la unión en un grado similar, independientemente del cemento de resina y tratamiento de superficie.

\section{Tabla I}

\section{La media (desviación estándar) de la fuerza de unión al cizallamiento en MPa}

\begin{tabular}{|lcccc|}
\hline Acondicionador & Cemento de Resina & \multicolumn{3}{c|}{ Tratamiento de Superficie } \\
\hline & & Ninguno & Arenado & Grabado Ácido \\
\hline Control & Panavia F2.0 & $17.0(3.5) \mathrm{Ab}$ & $22.3(5.2) \mathrm{Ba}$ & $15.8(3.5) \mathrm{Bb}$ \\
\hline & & $\mathrm{n}=10$ & $\mathrm{n}=10$ & $\mathrm{n}=8$ \\
\hline & RelyX U200 & $16.6(2.1) \mathrm{Ac}$ & $24.3(3.0) \mathrm{Aa}$ & $3.0(4.1) \mathrm{Ab}$ \\
\hline & & $\mathrm{n}=9$ & $\mathrm{n}=7$ & $\mathrm{n}=8$ \\
\hline Alloy Primer & Panavia F2.0 & $20.4(4.6) \mathrm{Ab}$ & $24.2(2.5) \mathrm{Ba}$ & $19.6(1.5) \mathrm{Bb}$ \\
\hline & & $\mathrm{n}=9$ & $\mathrm{n}=8$ & $\mathrm{n}=10$ \\
\hline & RelyX U200 & $21.0(3.3) \mathrm{Ac}$ & $26.6(2.4) \mathrm{Aa}$ & $20.7(6.4) \mathrm{Ab}$ \\
\hline & & $\mathrm{n}=9$ & $\mathrm{n}=10$ & $\mathrm{n}=7$ \\
\hline Metal Primer II & Panavia F2.0 & $21.8(3.0) \mathrm{Ab}$ & $26.1(3.9) \mathrm{Ba}$ & $19.8(3.2) \mathrm{Bb}$ \\
\hline & & $\mathrm{n}=9$ & $\mathrm{n}=9$ & $\mathrm{n}=9$ \\
\hline & RelyX U200 & $21.60(3.67) \mathrm{Ac}$ & $27.99(4.48) \mathrm{Aa}$ & $22.72(5.28) \mathrm{Ab}$ \\
\hline & & $\mathrm{n}=8$ & $\mathrm{n}=9$ & $\mathrm{n}=8$ \\
\hline Silano & $20.6(5.2) \mathrm{Ab}$ & $24.3(3.9) \mathrm{Ba}$ & $19.3(3.2) \mathrm{Bb}$ \\
\hline & Panavia F2.0 & $\mathrm{n}=7$ & $\mathrm{n}=9$ & $\mathrm{n}=9$ \\
\hline & & $20.7(3.4) \mathrm{Ac}$ & $26.5(3.5) \mathrm{Aa}$ & $23.0(3.0) \mathrm{Ab}$ \\
\hline & RelyX U200 & $\mathrm{n}=7$ & $\mathrm{n}=8$ & $\mathrm{n}=8$ \\
\hline
\end{tabular}

Coeficiente de variación $=15.57 \%$

Mismas letras no son estadísticamente diferentes (ANOVA de tres vías / Tukey, $\alpha=0,05$ ). Las letras mayúsculas comparan cementos de resina entre el tratamiento de superficielacondicionador. Las letras minúsculas comparan el tratamiento de superficie entre el cemento de resina/acondicionador.

En los grupos con tratamiento de la superficie (arenado y grabado ácido), el cemento de resina RelyX U200 presentó una fuerza de unión superior al cemento $\mathrm{Pa}$ navia F2.0. Ambos materiales presentaron resistencias de unión similares cuando se omitió el tratamiento de superficie. En los grupos cementados con Panavia F2.0, el arenado resultó en una fuerza de adhesión significativamente más alta, mientras que el grabado ácido y la ausencia de trata- miento de la superficie presentaron resultados similares. En los grupos cementados con el RelyX U200, hubo una diferencia significativa entre todos los tratamientos de superficie; el arenado presentó significativamente una fuerza adhesiva más alta, seguido del grabado ácido y la ausencia de tratamiento de superficie.

En la tabla 2 observamos la distribución de los modos de fallo en los grupos cementados con Panavia F2.0 y RelyX U200, 
respectivamente. Las fallas adhesivas eran más prevalentes en los 24 grupos experimentales, con un promedio de falla adhesiva de $78 \%$ entre la cerámica y el cemento de resina o entre el cemento resina y la interfaz con la dentina, encontrando que el $22 \%$ representaron fallas mixtas. No se observó ninguna falla cohesiva de los sustratos (cerámica, cementos de resina y la dentina).

\section{Tabla 2}

\section{Porcentaje de los modos de falla en cada grupo experimental}

\begin{tabular}{|ccccccccc}
\hline Cemento de Resina & Acondicionador & \multicolumn{7}{c}{ Tratamiento de Superficie } \\
\hline & & \multicolumn{2}{c}{ Ninguno } & \multicolumn{2}{c|}{ Arenado } & \multicolumn{2}{c|}{ Grabado Ácido } \\
\hline & & Adhesivo & Mezclado & Adhesivo & Mezclado & Adhesivo Mezclado \\
\hline Panavia F2.0 & Control & 70 & 30 & 71 & 29 & 78 & 22 \\
\hline & Alloy Primer & 75 & 25 & 75 & 25 & 71 & 29 \\
\hline & Metal Primer II & 70 & 30 & 67 & 33 & 75 & 25 \\
\hline Silano & 78 & 22 & 70 & 30 & 86 & 14 \\
\hline RelyX U200 & Control & 80 & 20 & 100 & 0 & 100 & 0 \\
\hline & Alloy Primer & 60 & 40 & 75 & 25 & 100 & 0 \\
\hline & Metal Primerll & 75 & 25 & 86 & 14 & 88 & 13 \\
\hline Silano & 70 & 30 & 83 & 17 & 71 & 29 \\
\hline
\end{tabular}

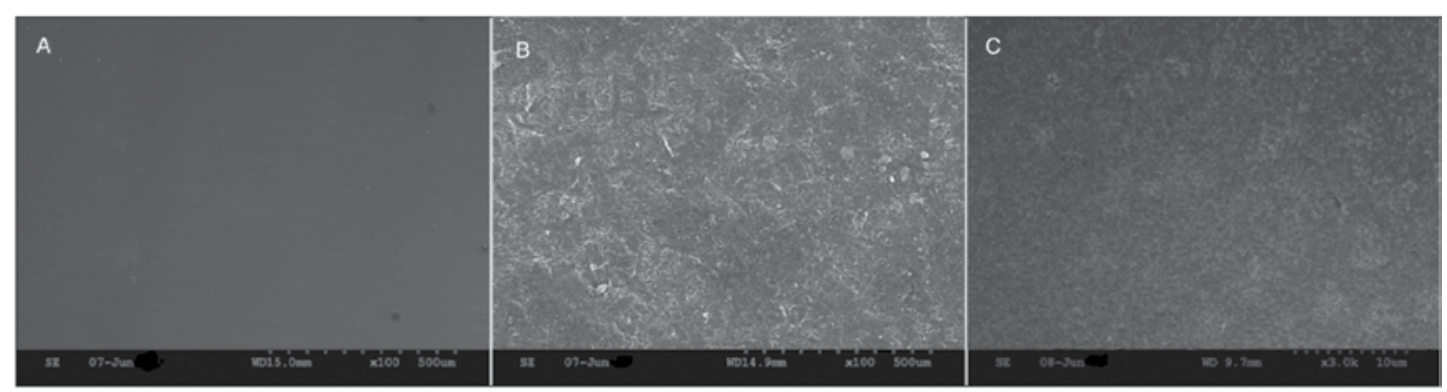

Figura 1: Imágenes de MEB (500x) de las superficies cerámicas. Figura 1A: Y-TZP superficie sin tratar (control) Figura 1B: Y-TZP superficie tratada con arenado de partículas de $53 \mu \mathrm{m} \mathrm{de} \mathrm{Al}_{2} \mathrm{O}_{3}$; Figura $1 \mathrm{C}$ : superficie de Y-TZP tratado con ácido fluorhídrico al $9.5 \%$

Las imágenes de MEB muestran diferencias morfológicas entre las placas de Y-TZP después de los tratamientos de superficie (Figura 2). El arenado por medio de aire a presión con partículas de $\mathrm{Al} 2 \mathrm{O} 3$ de 50 micras (Figura $2 b$ ) creó una superficie más áspera en comparación con la superficie de control y grabado ácido (Figuras 2a y 2c). El grabado ácido presentó una superficie lisa, con algunas pequeñas grietas perceptibles (Figura $2 \mathrm{c} /{ }^{*}$ ).

\section{| | | | | | | | | | | | | | | | | | | | | | | | | | | | | | | | | | | | | | | | | | | | | | | | | | | | | | | | | | | | | | | | | | | | | | | | | | | | | | | | | | | | | | | | | | | | | | | | | | | | | | | |}

\section{Discusión}

Existen estudios previos que han evaluado la resistencia de la unión de los materiales restauradores adhesivos y su interacción con la zirconia, en los que los métodos más utilizados para realizar estas evaluaciones fueron la resistencia al cizallamiento y la tracción. 1,3,5-6,10,15-16, 19-21 En ambos méto- 
dos, los especímenes tenían sólo una interfaz de adhesivo a ser estudiado, es decir, entre la superficie cerámica y el cemento de resina. Sin embargo, en una situación real en la clínica, están presentes las interfaces de la superficie de cerámica, el adhesivo o acondicionador, el cemento de resina y la estructura del diente. Por lo tanto, el rendimiento de la compleja unidad de las estructuras del diente, el cemento de resina y la zirconia debe ser estudiado con mayor profundidad. Durante las investigaciones preliminares para el estudio actual, las placas de Y- TZP se cementaron a las superficies de dentina, y estas muestras fueron seccionadas en la prueba de resistencia de la unión por microtensión. La incidencia de fallos prematuros durante el corte era muy alta (casi el $100 \%$ ), produciendo resultados poco fiables. Si el período que es necesario para la sección de las cerámicas Y- TZP densamente sinterizadas es largo, esto parece interferir y debilitar la interfaz de adhesivo, lo que resulta en las fallas prematuras. Para superar esta limitación y para poner a prueba las dos interfaces, se planteó una modificación de la prueba de resistencia al cizallamiento para el estudio actual. La prueba se realizó utilizando muestras de dentina recortadas en forma de disco y cementadas sobre placas de Y-TZP (Figura 1), en lugar del método convencional de microcizallamiento. ${ }^{23}$

Los tratamientos de superficie investigados en este estudio resultaron significativamente diferentes en cuanto a la fuerza de adhesión registrada. Por otra parte, las imágenes de MEB mostraron considerables diferencias cualitativas en la superficie de topografía de las placas de Y- TZP después de los tratamientos de superficie. Las imágenes mostraron que el arenado parece ser un método más eficiente para modificar superficies de zirconia en comparación con el grabado ácido, con los parámetros establecidos para este estudio. Este hallazgo puede estar directamente relacionado con los resultados de resistencia de adhesión, lo que demuestra que ambos cementos de resina dieron mayor fuerza de adherencia después de arenado. Algunas investigaciones también indican que es posible obtener una unión superior a la zirconia cuando las superficies son arenadas. ${ }^{5-6}$ Las superficies arenadas podrían presentar una mayor superficie, lo que favorece la capacidad de humectación. Sin embargo, algunos autores han afirmado que las microporosidades creadas por medio de tratamientos de superficie pueden actuar como iniciadores de grietas, lo que debilita los materiales cerámicos. ${ }^{12,20}$ Por lo tanto, el efecto de las alteraciones en la durabilidad de las restauraciones de Y-TZP deben ser estudiados en ensayos clínicos a largo plazo, para determinar si la mayor retención de las superficies arenadas pueden compensar los cambios en las propiedades mecánicas del material.

En este estudio, el grabado ácido de las superficies de $\mathrm{Y}$-TZP se propuso como un método de tratamiento de las superficies cerámicas, el cual se ha descrito en estudios previos, siendo uno de los métodos más utilizados durante los procedimientos clínicos. ${ }^{22} \mathrm{El}$ grabado ácido con ácido fluorhídrico al $9.5 \%$ para el tratamiento de superficies cerámicas es un método sencillo, sin necesidad de equipos especiales. El gran crecimiento de la utilización de restauraciones libres de metal ha hecho que este sistema para preparar las superficies cerámicas y obtener mejores resultados de unión se haya vuelto muy popular, sin embargo, su eficacia con las superficies cerámicas de zirconia, se ha descrito que puede variar dependiendo de su tipo. El presente estudio coincide con la investigación de Chaiyabutr Y y colaboradores, ya que pudimos observar que el grabado ácido con ácido fluorhídrico al $9.5 \%$ no ocasiona cambios importantes en la zirconia, como es el caso para la cerámica convencional que se utiliza en las restauraciones protésicas. 
Otra técnica utilizada de manera experimental es el tratamiento de superficies por medio de la irradiación con laser Er:YAG, el cual se dice que tiene la capacidad de eliminar las partículas de micro explosiones y vaporización, un proceso llamado ablación. Se ha encontrado que durante el tratamiento con láser, los cambios de temperatura locales debido a las fases de calentamiento y enfriamiento crean tensiones internas que pueden dañar el material. ${ }^{14}$ Las propiedades mecánicas de YTZP pueden ser afectadas negativamente por los cambios en la temperatura, ya que pueden inducir la fase de transformación. ${ }^{11}$ Por lo tanto, en el estudio actual se descartó la utilización de este método, debido al equipo necesario y la ineficacia para lograr el cambio de superficie deseado.

Los acondicionadores (primer para metales) fueron desarrollados como una alternativa para incrementar una unión más duradera y estable de los metales nobles con polímeros. ${ }^{18,24}$ El monómero VBATDT, un tautómero tiona-tiol, fue el primer producto presentado como una interfaz entre monómeros a base de metacrilato y aleaciones de metales nobles. ${ }^{25} \mathrm{El}$ mecanismo de acoplamiento de este monómero se lleva a cabo por la transformación de la tiona a grupos tiol sobre la superficie de metal noble, posteriormente por la formación de enlaces primarios y para la copolimerización de grupos vinilo con la resina a base de monómeros de metacrilato. ${ }^{24}$ Los acondicionadores utilizados en el presente estudio son agentes de acoplamiento de vinilo-tiona con diferentes monómeros funcionales. Además de sus distintas composiciones, los resultados de resistencia de adhesión indicaron un comportamiento similar para los tres sistemas, reforzando significativamente la unión con el Y-TZP para ambos cementos de resina. Este hallazgo podría sugerir que los agentes de acoplamiento de vinilo-tiona también presentan una afinidad química a las superficies de zirconia. En otros estudios previos se estableció que la aplicación de un adhesivo que contiene MDP con un agente de acoplamiento de silano es el factor clave para una unión confiable entre la resina y el Y-TZP, ya que esta unión no está influenciada por el agente de cementación de resina. ${ }^{3} \mathrm{La}$ unión-agente de silano mejora la humectabilidad de la superficie de la zirconia arenada. A pesar de que se utilizó un material cerámico diferente en nuestro estudio, el efecto y comportamiento de los acondicionadores se mostró similar, ya que éste aumenta la humectabilidad de la superficie de los cementos de resina.

En contraste con los resultados de algunos estudios previos que han demostrado que la afinidad química entre el material a base de MDP y el Y-TZP crea una unión fuerte que es capaz de resistir el envejecimiento térmico y almacenamiento en agua. ${ }^{1,5,10}$ En el estudio realizado, el cemento de resina con base MDP no presentó mayor resistencia a la adherencia a las superficies Y-TZP en comparación con el material a base de Bis-GMA. Ambos cementos mostraron resultados similares sólo en las muestras con superficies no tratadas, mientras que en las superficies de arenado y grabado ácido, el cemento de resina con base Bis-GMA mostró una unión significativamente más fuerte. Uno de los componentes del sistema de adhesivo utilizado junto con el cemento de resina con base Bis-GMA es un monómero monofosfato (PENTA). El enlace químico entre los grupos fosfato y dióxido de circonio ha sido reportado, ${ }^{1,5,15}$ y podría ser una razón para futuros estudios donde se compare la unión entre ambos cementos de resina en las superficies tratadas. Sin embargo, otras investigaciones indican que la unión de Bis-GMA y los compuestos de óxido de circonio no es resistente al almacenamiento a largo plazo y envejecimiento térmico. ${ }^{1,10}$ En el estudio actual, sólo la resistencia de la unión inmediata (medido 24 horas des- 
pués de la polimerización de los cementos de resina) se puso a prueba. Puesto que un período de exposición de agua de sólo 24 horas es insuficiente para permitir la difusión de agua en la interfaz adhesiva, se debe considerar que los diferentes resultados se pudieron haber detectado si las muestras se hubieran sometido a un protocolo de envejecimiento. Por lo tanto, se sugiere que es necesario realizar más estudios in vitro con largos períodos de almacenamiento para determinar la durabilidad a largo plazo de la unión.
Los resultados indicaron que el modo de fallo sin importar el grupo experimental, -la mayoría de los fracasos de la compleja estructura formada por el diente-cemento de resina-Y-TZP- fue el adhesivo, ya que se mostró ausente y sin residuos en las placas de zirconia. Este hallazgo podría sugerir que, incluso cuando se obtiene mayor resistencia de unión con la zirconia, esta unión no es tan fuerte como la adhesión entre la dentina y el material de restauración.

\section{Conclusiones}

A pesar de las limitaciones de este estudio, se pudieron concluir los siguientes puntos:

- Las hipótesis analizadas fueron rechazadas, ya que los tratamientos de superficie y la aplicación de acondicionadores influyeron significativamente en la resistencia de la unión a la zirconia.

- Los acondicionadores y el arenado por medio de partículas de $50 \mu \mathrm{m}$ de $\mathrm{Al}_{2} \mathrm{O}_{3}$ pueden tener un efecto sinérgico sobre la unión entre la dentina y la cerámica de Y-TZP.

- Los cementos de resina con base Bis-GMA presentaron un vínculo inmediato más fuerte en las superficies tratadas que el material con base MDP.

\section{Bibliografía}

1. Luthy $\mathrm{H}$, Loeffel $\mathrm{O}$ \& Hammerle $\mathrm{CH}$ (2006) Effect of thermo- cycling on bond strength of luting cements to zirconia ceram- ic Dental Materials 22(2) 195 200.

2. Piconi C \& Maccauro G (1999) Zirconia as a ceramic bioma- terial Biomaterials 20(1) 1-25.

3. Blatz MB, Sadan A, Martin J \& Lang B (2004) In vitro eval- uation of shear bond strengths of resin to densely-sintered high-purity zirconium-oxide ceramic after long-term storage and thermal cycling The Journal of Prosthetic Dentistry 91(4) 356-362.

4. Guazzato $M$, Albakry $M$, Ringer SP \& Swain MV (2004) Strength, fracture toughness and microstructure of a selec- tion of all-ceramic materials Part II Zirconia-based dental ceramics Dental Materials 20(5) 449-456.

5. Wolfart M, Lehmann F, Wolfart S \& Kern M (2007) Durability of the resin bond strength to zirconia ceramic after using different surface conditioning methods Dental Materials 23(1) 45-50.

6. Ozcan M, Kerkdijk S \& Valandro LF (2007) Comparison of resin cement adhesion to Y-TZP ceramic following manufac- turers' instructions of the cements only Clinical Oral Investigations 13(3) 279-282.

7. Yilmaz H, Aydin C \& Gul BE (2007) Flexural strength and fracture toughness of dental core ceramics The Journal of Prosthetic Dentistry 98(2) 120-128.

8. Papanagiotou HP, Morgano SM, Giordano RA \& Pober R (2006) In vitro evaluation of low-temperature aging effects and finishing procedures on the flexural strength and struc- tural stability of Y-TZP dental ceramics The Journal of Prosthetic Dentistry 96(3) 154164.

9. Tinschert J, Natt G, Mautsch W, Augthun M \& Spiekermann $\mathrm{H}$ (2001) Fracture resistance of lithium disilicate-, alumina-, and zirconia-based three-unit fixed partial dentures: A labo- ratory study International Journal of Prosthodontics 14(3) 231-238. 
10. Kern M \& Wegner SM (1998) Bonding to zirconia ceramic: Adhesion methods and their durability Dental Materials 14(1) 64-71.

11. Guazzato $M$, Quach $L$, Albakry $M$ \& Swain $M V$ (2005) Influence of surface and heat treatments on the flexural strength of Y-TZP dental ceramic Journal of Dentistry 33(1) 9-18.

12. Zhang $Y$, Lawn BR, Rekow ED \& Thompson VP (2004) Effect of sandblasting on the long-term performance of dental ceramics Journal of Biomedical Materials Research Part B: Applied Biomaterials 71(2) 381-386.

13. Burnett LH Jr, Shinkai RS \& Eduardo Cde P (2004) Tensile bond strength of a one-bottle adhesive system to indirect composites treated with Er:YAG laser, air abrasion, or fluo- ridric acid Photomedicine and Laser Surgery 22(4) 351-356.

14. Gokce B, Ozpinar B, Dundar M, Comlekoglu E, Sen $\mathrm{BH} \&$ Gungor MA (2007) Bond strengths of all-ceramics: Acid vs laser etching Operative Dentistry 32(2) 173-178.

15. Yoshida K, Tsuo $Y$ \& Atsuta $M$ (2006) Bonding of dual-cured resin cement to zirconia ceramic using phosphate acid ester monomer and zirconate coupler Journal of Biomedical Materials Research Part B: Applied Biomaterials 77(1) 28-33.

16. Atsu SS, Kilicarslan MA, Kucukesmen HC \& Aka PS (2006) Effect of zirconium-oxide ceramic surface treatments on the bond strength to adhesive resin The Journal of Prosthetic Dentistry 95(6) 430-436.

17. 17.Matsumura $H$, Kamada $K$, Tanoue $N$ \& Atsuta $M$ (2000) Effect of thione primers on bonding of noble metal alloys with an adhesive resin Journal of Dentis- try 28(4) 287-293.

18. Yoshida K, Kamada K, Sawase T \& Atsuta M (2001) Effect of three adhesive primers for a noble metal on the shear bond strengths of three resin cements Journal of Oral Rehabilitation 28(1) 14-19.

19. Piwowarczyk A, Lauer HC \& Sorensen JA (2005) The shear bond strength between luting cements and zirconia ceramics after two pre-treatments Operative Dentistry 30(3) 382-388.

20. Kumbuloglu O, Lassila LV, User A \& Vallittu PK (2006) Bonding of resin composite luting cements to zirconium oxide by two air-particle abrasion methods Operative Dentistry 31(2) 248-255.

21. Quaas AC, Yang B \& Kern M (2007) Panavia F 2.0 bonding to contaminated zirconia ceramic after different cleaning proce- dures Dental Materials 23(4) 506-512.

22. Chaiyabutr Y, McGowan S, Phillips KM, Kois JC, Giordano RA. (2008) The effect of hydrofluoric acid surface treatment and bond strength of a zirconia veneering ceramic. The Journal of Prosthetic Dentistry 100(3) 194-202

23. Shimada Y, Yamaguchi S \& Tagami J (2002) Microshear bond strength of dual-cured resin cement to glass ceramics Dental Materials 18(5) 380-388.

24. Silikas $N$, Wincott $P L$, Vaughan $D$, Watts $D C$ \& Eliades $G$ (2007) Surface characterization of precious alloys treated with thione metal primers Dental Materials 23(6) 665-673.

25. Kojima K, Kadoma Y \& Imai Y (1987) Adhesion to precious metals utilizing triazine dithione derivative monomer The Journal of the Japanese Society for Dental Materials and Devices 6 702-707. 